\title{
Breast cancer brain metastases: the last frontier
}

\author{
José Pablo Leone ${ }^{1 *}$ and Bernardo Amadeo Leone ${ }^{2}$
}

\begin{abstract}
Breast cancer is a common cause of brain metastases, with metastases occurring in at least 10-16\% of patients. Longer survival of patients with metastatic breast cancer and the use of better imaging techniques are associated with an increased incidence of brain metastases. Unfortunately, patients who develop brain metastases tend to have poor prognosis with short overall survival. In addition, brain metastases are a major cause of morbidity, associated with progressive neurologic deficits that result in a reduced quality of life. Tumor subtypes play a key role in prognosis and treatment selection. Current therapies include surgery, whole-brain radiation therapy, stereotactic radiosurgery, chemotherapy and targeted therapies. However, the timing and appropriate use of these therapies is controversial and careful patient selection by using available prognostic tools is extremely important. This review will focus on current treatment options, novel therapies, future approaches and ongoing clinical trials for patients with breast cancer brain metastases.
\end{abstract}

Keywords: Breast cancer, Brain metastasis, Metastatic breast cancer

\section{Background}

Breast cancer represents the second most frequent cause of brain metastases after lung cancer, with metastases occurring in 10-16\% of patients [1]. In addition, autopsy studies have demonstrated another $10 \%$ which were asymptomatic [2]. The incidence of brain metastases seem to have increased in recent years, this is likely due to prolonged survival of patients receiving more efficient treatments and the availability of better imaging techniques that lead to increased detection of brain metastases.

The development of brain metastases is a complex process, requiring invasion of the primary breast cancer cells into surrounding tissue and vessels, traffic through the circulatory system and colonization and growth in the brain parenchyma $[3,4]$. In breast cancer, this process takes a median of 32 months from the initial cancer diagnosis [5]; which shows that the breast cancer tumor cells, unlike other cancer cells, need more time to develop

\footnotetext{
*Correspondence: jose-leone@uiowa.edu

${ }^{1}$ University of lowa Holden Comprehensive Cancer Center, University of lowa Hospitals and Clinics, C32 GH, 200 Hawkins Drive, lowa City, IA 52242, USA

Full list of author information is available at the end of the article
}

the ability to penetrate through the blood-brain barrier (BBB) and colonize the brain. There is also a selective pressure that can make the brain a preferential site of metastasis, as many of our currently available therapies are unable to cross the $\mathrm{BBB}$, even if this barrier is disrupted by tumor invasion.

Previous studies have identified the subgroups of patients with triple-negative and human epidermal growth factor receptor 2 (HER2)-positive breast cancer as having an increased risk for the development of brain metastases [6-9], with up to half of patients with HER2-positive metastatic breast cancer experiencing brain metastases over time [10]. Tumor subtypes are also an important factor for the median time interval from primary diagnosis to development of brain metastases; a recent large study showed shorter intervals for triplenegative and HER2-positive patients, and longer intervals for estrogen receptor (ER) positive tumors [11].

Brain metastases in breast cancer patients represent a catastrophic event that portends a poor prognosis, with a median survival that ranges from 2 to 25.3 months despite treatment $[5,12-14]$. In addition, brain metastases are a major cause of morbidity, associated with progressive neurologic deficits that result in a reduced 
quality of life [15]. With the advent of better systemic therapies, brain metastases constitute an increasing clinical problem. This is particularly important in HER2-positive patients, in whom brain metastases can occur in the setting of controlled extracranial disease [16]. In contrast, it is common for patients with triple-negative breast cancer to develop brain metastases with concurrent extracranial disease progression [17]. Treatment options for patients with breast cancer brain metastases are limited and include surgical resection, whole-brain radiation therapy (WBRT), stereotactic radiosurgery (SRS), chemotherapy and targeted therapy $[12,18,19]$. This review will focus on the key issues of current treatment options, comment on novel therapies and ongoing clinical trials for patients with breast cancer brain metastases.

\section{Prognostic factors}

The prognosis of patients with breast cancer who develop brain metastases is affected by several factors. Tumor subtypes have been identified as a prognostic factor for overall survival in brain metastases [20,21]. Triplenegative breast cancer patients have the shortest survival ranging from 3 to 4 months $[9,16,22]$. In contrast, patients with HER2-positive tumors have longer survival than those with triple-negative or luminal subtypes, although their rates of brain metastases are higher $[9,16$, 23].

Another important prognostic factor is the performance status of the patient at the time of diagnosis of brain metastases. Most studies have established the utility of the Karnofsky Performance Status (KPS) as a tool to assess prognosis and identified that patients with longer survival have KPS scores $\geq 70$ [13, 14, 24]. In addition to the KPS, patient's age can also affect prognosis. Older age at the time of initial breast cancer diagnosis has been associated with shorter overall survival and shorter survival from the time of first tumor relapse [5, 25]. Finally, the burden of disease represented by the number of brain metastases, as well as the presence of uncontrolled extracranial disease have both been related with worse prognosis [23, 24, 26].

One of the most frequently used tools for the assessment of prognosis in brain metastases is the graded prognostic assessment (GPA) [27]. This prognostic index includes age, KPS score, number of brain metastases and extracranial metastases. After its original validation [28], the index was modified to create a breast cancer-specific GPA that included tumor subtypes among its prognostic factors [11, 14]. However, number of brain metastases was not incorporated into the final model. A recent study validated the breast cancer-specific GPA and refined it with the addition of number of brain metastases [29].
This represents a very useful tool for patient risk assessment and selection for clinical trials.

\section{Local therapy modalities Surgical resection}

Surgical resection of the brain metastasis is an important treatment option in patients with single or few $(\leq 3)$ lesions. Particularly when the systemic disease is well controlled and when the brain metastases are symptomatic. Although the anatomic location of the metastatic lesion can be a limitation, surgical resection has additional advantages including the potential for immediate improvement of focal deficits, relief of intracranial hypertension and establishment of histological diagnosis in patients with no other site of metastasis.

One of the first studies to evaluate the role of surgical resection in brain metastasis was conducted by Patchell et al. [30]. In this study, 48 patients with single brain metastasis from any primary were randomized to either surgical resection of the brain metastasis followed by WBRT or needle biopsy followed by WBRT. Brain recurrence was less frequent in the surgery group compared with the radiation group ( 20 vs. $52 \%$, respectively; $P<0.02)$. Median overall survival was longer in the surgery group (40 weeks) compared with the radiation group (15 weeks) $(P<0.01)$. Neurological outcomes were also improved with surgery where patients remained functionally independent longer (median, 38 vs. 8 weeks in the radiation group; $P<0.005$ ).

A subsequent study randomized 63 patients with systemic cancer and a single brain metastasis to surgical resection plus WBRT vs. WBRT alone. The combined modality led to longer overall survival and longer functionally independent survival compared with WBRT alone, particularly in patients with stable extracranial disease (median overall survival 12 vs. 7 months, respectively; median functionally independent survival 9 vs. 4 months, respectively) [31]. Patients with progressive extracranial disease had similar outcomes irrespective of treatment, a finding that was also observed in another randomized trial [32]. Three non-randomized studies have also confirmed improvements in survival, brain recurrence and neurological outcomes with surgical resection in addition to WBRT [33-35].

\section{Stereotactic radiosurgery}

In patients with limited brain metastases who are deemed poor candidates for surgical resection or who have lesions in difficult anatomic locations, SRS has been proposed as an alternative treatment option. This approach delivers a high-precision photon radiation to a small target volume while sparing most normal brain tissues. SRS 
has an advantage over WBRT in that it avoids the feared toxicity of neurocognitive decline that is associated with the latter intervention [36-38].

The efficacy of SRS for local control of brain metastases has been demonstrated in a study conducted by Kondziolka et al. [36], were median time to local failure in patients with two to four brain metastases was significantly improved from 6 months with WBRT alone to 36 months with the addition of SRS $(P=0.0005)$. In spite of this improvement in local control, overall survival was unchanged and was related to the extent of extracranial disease. The Radiation Therapy Oncology Group (RTOG) confirmed the efficacy of SRS in addition to WBRT in patients with one to three brain metastases and documented an overall survival improvement of 1.6 months in the subgroup of patients with single unresectable brain metastasis who received the combined therapy [39]. In patients with solitary metastases who are treated with surgical resection plus WBRT, the addition of SRS to the tumor bed can improve local control [40].

Subsequent randomized studies that included brain metastases from different cancers demonstrated that patients with one to four lesions who were treated with SRS alone had similar survival and improved neurocognition compared with patients who received both SRS and WBRT, however local control was inferior with SRS alone $[41,42]$. These results were confirmed in a metaanalysis [43]. A recent non-randomized non-inferiority trial showed the efficacy of SRS without WBRT for overall survival in patients with five to ten brain metastases to be not inferior to the same treatment in patients with two to four lesions [44]. Despite the findings of this study and others showing similar clinical outcomes [45-47], currently there is no randomized data to support the use of SRS without WBRT in the treatment of brain metastases for patients with $>4$ lesions.

\section{Whole-brain radiation therapy}

One of the most important treatments available for brain metastases is WBRT, particularly in the setting of multiple brain lesions. This approach has two main goals-the control of macroscopic metastases, and the eradication of microscopic seeding of the brain. The majority of patients are given conventional WBRT, a total dose of 30 Gy in 10 fractions with daily fractions of 3-4 Gy [48].

The benefit of WBRT after surgical resection has been demonstrated in a prospective trial that randomized 95 patients who had single brain metastases to WBRT or observation [49]. The study showed that patients in the WBRT group had fewer recurrences both at the operative site (10 vs. $46 \%, P<0.001)$ and at other sites in the brain (14 vs. $37 \%, P<0.01$ ), however overall survival was not increased.
Substantial controversy exists about the role of WBRT in patients with few $(\leq 4)$ brain metastases. In this setting, treatment with WBRT after surgical resection or SRS resulted in fewer intracranial recurrences, but there was no difference in overall survival $[41,50]$. Associated toxicities with WBRT included worse neurocognitive outcomes and quality of life [42, 51]. However, withholding WBRT can lead to progressive disease in the brain, which in turn could also negatively impact cognition [52, 53]. This issue was addressed in a study conducted by the North Central Cancer Treatment Group (NCCTG) N0574 where patients with one to three brain metastases were randomized to SRS or SRS plus WBRT, the study showed more frequent decline in cognitive function with the addition of WBRT despite better brain control [54]. Therefore, delaying or avoiding the administration of WBRT in metastatic breast cancer after surgical resection or SRS through the careful use of effective systemic therapies, could provide substantial benefits in terms of quality of life, particularly in patients with high GPA scores in whom survival is expected to be longer [14, 29]. This approach results even more appealing when one considers that none of the above mentioned randomized trials have shown overall survival gain with the addition of WBRT.

\section{Systemic therapies}

The mainstay of systemic treatment for breast cancer brain metastases is cytotoxic chemotherapy; however, there are currently additional options for targeted therapy. Therefore, it is crucial to consider the tumor subtype not only for prognosis but also to understand the different options for systemic therapies.

\section{Hormone receptor-positive}

Patients with ER-positive brain metastases derive substantial benefit from systemic chemotherapy. Niwinska et al. reported improvements in median survival from 3 to 14 months with the addition of systemic therapy in patients with luminal breast cancer [20]. A similar result was seen in another study where the median overall survival of patients with luminal breast cancer was improved from 7.1 to 14.3 months with chemotherapy [55].

The efficacy of endocrine therapy for brain metastases is less clear, since most randomized trials testing this intervention excluded these patients. Despite of this, there are some reports showing response of brain metastases to tamoxifen, megestrol acetate and aromatase inhibitors [56-61]. Interestingly, tamoxifen and its metabolites can achieve high concentrations in the brain. Lien et al. showed that the concentrations were up to 46-fold higher in the brain metastatic tumor and brain tissue than in serum [62]. Taken together, these data 
support the hypothesis that in patients with metastatic ER-positive breast cancer who have asymptomatic systemic disease and locally treated brain metastases treatment with endocrine therapy could be considered prior to systemic chemotherapy. Clinical trials evaluating this approach should be conducted.

\section{HER2-positive}

Patients with HER2-positive metastatic breast cancer have experienced a dramatic improvement in overall survival with optimal the utilization of HER2 targeted therapy [63]. Unfortunately, the advances in systemic treatments for these patients came in hand with an increase in the rate of brain metastases, which now poses a significant threat [10]. The efficacy of anti-HER2 therapy to control systemic disease for longer periods of time has exposed the ability of the HER2-positive breast cancer cells to seed the brain parenchyma and develop brain metastases. Most chemotherapy agents and HER2 targeted therapies do not cross the intact $\mathrm{BBB}$ or are pumped out of the central nervous system (CNS) by $\mathrm{P}$-glycoproteins present in the BBB, therefore they may not reach sufficient therapeutic levels to eradicate metastatic cells [1]. For example, in patients without brain metastases, the ratio of trastuzumab in plasma to trastuzumab in cerebrospinal fluid is $>300: 1[64,65]$. The brain then, can serve as a sanctuary where those cells that have the ability to seed can escape the cytotoxic efficacy of systemic therapy. However, tumor growth in the brain as well as cranial surgery and brain radiotherapy can disrupt the BBB and allow access of systemic drugs to the tumor. This concept has been proven by a number of labeled-trastuzumab imaging studies [66, 67]. Also, several clinical studies have shown that the combination of chemotherapy with trastuzumab improved survival, even after the development of brain metastases [68-70]. This benefit is presumed to be mainly due to improved control of systemic disease [71].

Lapatinib, a small molecule with potential ability to cross the $\mathrm{BBB}$, has been extensively tested in the treatment of HER2-positive brain metastases. As a single agent, lapatinib has shown response rates in the brain ranging from 2.6 to $6 \%$ in heavily pre-treated patients $[72,73]$. However, when added to capecitabine, response rates increase to 20 to $33 \%$ [73-77]. The highest efficacy is observed in previously untreated patients, where the combination of lapatinib and capecitabine produces an objective response rate of $65.9 \%$, with a median time to progression of 5.5 months and a 1-year survival rate $>70 \%$ [78]. This drug combination has also shown to reduce the rate of brain metastases as the first site of progression from $6 \%$ with capecitabine alone to $2 \%$ with capecitabine and trastuzumab $(P=0.045)$ [79]. The efficacy of lapatinib to prevent brain metastases was further tested in the CEREBEL trial, where patients with HER2-positive metastatic breast cancer without CNS metastases were randomized to lapatinib or trastuzumab in combination with capecitabine. The primary end point of the study was incidence of CNS metastases as first site of relapse. The study was terminated early and showed no difference between arms for the incidence of CNS metastases (3\% for lapatinib vs. $5 \%$ for trastuzumab, $P=0.36$ ), however progression-free survival and overall survival were longer with trastuzumab and capecitabine [80]. Despite the low incidence of CNS metastases seen during the study, it is important to notice that $4.7 \%$ of all screened patients were excluded due to detection of asymptomatic brain metastases.

In the EMILIA trial, Trastuzumab emtansine (T-DM1), a novel antibody-drug conjugate, improved overall survival compared with lapatinib plus capecitabine in patients with previously treated HER2-positive metastatic breast cancer [81]. A recent retrospective, exploratory analysis of this trial focusing on patients with baseline CNS metastases, showed that the rate of CNS progression was similar for both arms, however median overall survival in patients with CNS metastases at baseline was significantly improved with T-DM1 (26.8 vs. 12.9 months, $P=0.008$ ) [82]. Similar results were seen in the CLEOPATRA trial, where patients with HER2positive first line metastatic breast cancer experienced significant improvements in progression-free and overall survival with pertuzumab, trastuzumab and docetaxel compared with placebo, trastuzumab and docetaxel [63]. In this trial, an exploratory analysis of the incidence and time to development of CNS metastases as first site of disease progression, also showed that the incidence was similar between the two arms, however the time to development of CNS metastases was significantly prolonged in the pertuzumab arm from 11.9 to 15 months $(P=0.0049)$ [83]. Taken together, the data from EMILIA and CLEOPATRA underscore the importance of systemic disease control for improving overall survival in patients with brain metastases.

Given the high prevalence and impact that brain metastases cause in patients with HER2-positive breast cancer, the American Society of Clinical Oncology (ASCO) published in 2014 its first clinical practice guideline on the management of patients with HER2-positive brain metastases [84]. Some of the key recommendations included the following: (a) for patients with progressive intracranial metastases, options include a trial of systemic therapy in addition to other local therapy modalities; (b) for patients whose systemic disease is not progressive at the time of brain metastasis diagnosis, systemic therapy should not be changed; (c) for patients 
whose systemic disease is progressive at the time of brain metastasis diagnosis, treatment should include HER2targeted therapy according to the algorithms for treatment of HER2-positive metastatic breast cancer [85].

\section{Triple-negative}

Patients with brain metastases from triple-negative breast cancer unfortunately lack targeted therapies and chemotherapy is currently their only systemic option.

Some of the initial studies of patients with brain metastases have shown objective response rates of around $50 \%$ with traditional chemotherapy combinations $[86,87]$. A study evaluating cisplatin with etoposide showed $38 \%$ response rate in the brain [88]. Topotecan and temozolamide have failed to show responses as single agent [89, 90]. However, when temozolamide was combined with cisplatin had $40 \%$ response rate [91], and showed $18 \%$ response rate when combined with capecitabine [92]. The experience with single agent capecitabine is limited to mostly retrospective studies [93].

It is important to keep in mind that while different chemotherapies will defer in their ability to penetrate the $\mathrm{BBB}$, most brain metastases will significantly disrupt this barrier. Therefore the ability to deliver systemic chemotherapy to the brain metastasis is not much different from the ability to deliver chemotherapy to that tumor anywhere else in the body. Hence, treatment efficacy is more closely related to tumor chemosensitivity than to the drug ability to cross an intact BBB and this hypothesis has been proven in several of the above mentioned studies [86-88]. Brain metastases tend to be chemotherapy-resistant because they tend to occur late in the natural history of breast cancer and by that point many times the breast cancer is already chemotherapy-resistant.

\section{Suggested treatment approach}

Based on the evidence reviewed above, we suggest the following management approach:

a. For patients with a single brain metastasis, surgical resection can improve overall survival, particularly in symptomatic patients when systemic disease is well controlled. The addition of SRS to the tumor bed or WBRT improve local control.

b. For patients with one to four brain metastases, SRS with or without WBRT should be considered to improve local control. If WBRT is added, we recommend to delay its administration as much as possible to prevent neurocognitive decline, which is particularly important in the absence of overall survival benefit. Surgery can be considered for large or symptomatic lesions. c. For patients with more than four brain metastases, WBRT can be the treatment of choice to palliate symptoms and improve local control. There are no randomized trials to support the use of SRS in this setting.

d. For patients with progressive systemic disease at the time of development of brain metastases, a change in systemic therapy should be considered based on the tumor subtype.

e. For patients with non-progressive systemic disease at the time of development of brain metastases, systemic therapy should not be changed.

f. For each patient, the choice of systemic therapy should be considered based on the tumor subtype.

g. For patients with poor prognosis, options include WBRT and/or best supportive care.

\section{Novel approaches and future directions}

Given the paucity of effective treatment options for patients with breast cancer brain metastases, this currently represents an area of great potential for future research. The use of bevacizumab has shown good results in patients with glioblastoma and has made the strategy of blocking the vascular endothelial growth factor (VEGF) pathway an interesting alternative to treat brain metastases. Two studies evaluating this approach have been reported. One showed CNS response rate of $63 \%$ for bevacizumab and carboplatin; and the other one showed a response rate of $60 \%$ for bevacizumab, etoposide and cisplatin $[94,95]$. It is important to consider that VEGF blockade rises a number of controversies. One of the most concerning being that meta-analyses have failed to show an overall survival benefit with the use of bevacizumab in metastatic breast cancer, which resulted in the US Food and Drug Administration (FDA) withdrawal of the conditional approval of the drug.

The high affinity folate receptor (HFR) is a novel target present in $33 \%$ of breast cancers for which there are available drugs being evaluated. Despite of the initial excitement, a recent study showed very low levels of expression in brain metastases [96]. Another approach that is currently under study in patients with breast cancer brain metastases is targeting the phosphatidylinositol 3-kinase (PI3K)-mammalian target of rapamycin (mTOR) pathway. This is one of the most commonly altered pathways not only in metastatic breast cancer but also in brain metastases [97]. Everolimus is being evaluated in combination with capecitabine and lapatinib (NCT01783756) and in combination with vinorelbine and trastuzumab (NCT01305941) in patients with HER2positive brain metastases.

Given the high incidence of brain metastases, particularly for patients with HER2-positive and triple-negative breast 
cancer, there have been efforts to develop strategies for prevention of brain metastases in the high-risk subgroups. Much of these have evolved around the concept of using prophylactic cranial irradiation (PCI) in patients with these breast cancer subtypes, similar to what is currently done for patients with small cell lung cancer. However, as mentioned earlier in this article, the timing of development of brain metastases in patients with HER2-positive and triplenegative breast cancer is not the same, nor is the same their survival after development of metastatic disease. In addition, given the cognitive effects of brain radiotherapy, there is significant controversy around the optimal timing of PCI.

Table 1 shows a summary of currently ongoing studies evaluating different treatment strategies in breast cancer brain metastases.

\section{Conclusions}

Brain metastases are an increasing problem in breast cancer. They represent an unmet need for which more efficacious therapies are urgently required. A better understanding of the molecular underpinnings of CNS progression is needed and ongoing studies analyzing matched tissue from primary and brain metastases will hopefully shed light on this. Traditionally, patients with brain metastases were excluded from clinical trials evaluating systemic therapies and we are left with the unanswered question of how efficacious those therapies would be for patients with brain metastases. To this end, the large number of ongoing breast cancer-specific brain metastases trials is a step in the right direction.

Table 1 Ongoing clinical trials in breast cancer brain metastases

\begin{tabular}{|c|c|c|c|c|}
\hline Tumor subtype & $\begin{array}{l}\text { Treatment/ } \\
\text { target }\end{array}$ & Experimental arm & Control arm & $\begin{array}{l}\text { Clinicaltrials.gov ID/ } \\
\text { phase }\end{array}$ \\
\hline \multirow[t]{12}{*}{ All } & \multirow[t]{5}{*}{ Chemotherapy } & Cabazitaxel & None & $\begin{array}{l}\text { NCT02166658 } \\
\text { Phase II }\end{array}$ \\
\hline & & TPI 287 & None & $\begin{array}{l}\text { NCT01332630 } \\
\text { Phase II }\end{array}$ \\
\hline & & ANG1005 & None & $\begin{array}{l}\text { NCT02048059 } \\
\text { Phase II }\end{array}$ \\
\hline & & ANG1005 + trastuzumab (if HER2-positive) & None & $\begin{array}{l}\text { NCT01480583 } \\
\text { Phase II }\end{array}$ \\
\hline & & Liposomal cytarabine + high-dose methotrexate & None & $\begin{array}{l}\text { NCT00992602 } \\
\text { Phase II }\end{array}$ \\
\hline & \multirow[t]{4}{*}{ VEGF } & $\begin{array}{l}\text { Bevacizumab + carboplatin + trastuzumab (if HER2- } \\
\text { positive) }\end{array}$ & None & $\begin{array}{l}\text { NCT01004172 } \\
\text { Phase II }\end{array}$ \\
\hline & & Bevacizumab + etoposide + cisplatin followed by WBRT & WBRT alone & $\begin{array}{l}\text { NCT02185352 } \\
\text { Phase II }\end{array}$ \\
\hline & & Sorafenib + WBRT & None & $\begin{array}{l}\text { NCT01724606 } \\
\text { Phase I }\end{array}$ \\
\hline & & Cabozantinib + trastuzumab (if HER2-positive) & None & $\begin{array}{l}\text { NCT02260531 } \\
\text { Phase II }\end{array}$ \\
\hline & \multirow[t]{3}{*}{ Radiation } & WBRT + temozolamide & None & $\begin{array}{l}\text { NCT02133677 } \\
\text { Phase II }\end{array}$ \\
\hline & & WBRT with hippocampal avoidance & Conventional WBRT & $\begin{array}{l}\text { NCT01942980 } \\
\text { Phase III }\end{array}$ \\
\hline & & WBRT + efaproxiral + oxygen & WBRT + oxygen & $\begin{array}{l}\text { NCT00083304 } \\
\text { Phase III }\end{array}$ \\
\hline \multirow[t]{6}{*}{ HER2-positive } & Chemotherapy & Cabazitaxel + lapatinib & None & $\begin{array}{l}\text { NCT01934894 } \\
\text { Phase II }\end{array}$ \\
\hline & \multirow[t]{5}{*}{ HER2 } & Lapatinib + WBRT & WBRT alone & $\begin{array}{l}\text { NCT01622868 } \\
\text { Phase II }\end{array}$ \\
\hline & & Neratinib \pm capecitabine & None & $\begin{array}{l}\text { NCT01494662 } \\
\text { Phase II }\end{array}$ \\
\hline & & Afatinib \pm vinorelbine & Investigator's choice & $\begin{array}{l}\text { NCT01441596 } \\
\text { Phase II }\end{array}$ \\
\hline & & T-DM1 + WBRT & None & $\begin{array}{l}\text { NCT02135159 } \\
\text { Phase I }\end{array}$ \\
\hline & & ARRY-380 + trastuzumab & None & $\begin{array}{l}\text { NCT01921335 } \\
\text { Phase I }\end{array}$ \\
\hline
\end{tabular}


Table 1 continued

\begin{tabular}{|c|c|c|c|c|}
\hline Tumor subtype & $\begin{array}{l}\text { Treatment/ } \\
\text { target }\end{array}$ & Experimental arm & Control arm & $\begin{array}{l}\text { Clinicaltrials.gov ID/ } \\
\text { phase }\end{array}$ \\
\hline & \multirow[t]{2}{*}{ mTOR } & Everolimus + trastuzumab + vinorelbine & None & $\begin{array}{l}\text { NCT01305941 } \\
\text { Phase II }\end{array}$ \\
\hline & & Everolimus + lapatinib + capecitabine & None & $\begin{array}{l}\text { NCT01783756 } \\
\text { Phase lb/ll }\end{array}$ \\
\hline & PI3K & BKM120 + trastuzumab \pm capecitabine & None & $\begin{array}{l}\text { NCT01132664 } \\
\text { Phase lb/ll }\end{array}$ \\
\hline & MET & Tesevatinib + trastuzumab & None & $\begin{array}{l}\text { NCT02154529 } \\
\text { Phase lb/lla }\end{array}$ \\
\hline & Radiation & $\mathrm{PCl}$ & None & $\begin{array}{l}\text { NCT00916877 } \\
\text { Phase I }\end{array}$ \\
\hline & & $\mathrm{PCl}+$ taxane + trastuzumab & $\begin{array}{l}\text { Taxane }+ \text { trastu- } \\
\text { zumab }\end{array}$ & $\begin{array}{l}\text { NCT00639366 } \\
\text { Phase III }\end{array}$ \\
\hline & & SRS + HER2 directed therapy & None & $\begin{array}{l}\text { NCT01924351 } \\
\text { Phase II }\end{array}$ \\
\hline \multirow[t]{3}{*}{ Triple-negative } & PI3K & BKM120 + capecitabine & None & $\begin{array}{l}\text { NCT02000882 } \\
\text { Phase II }\end{array}$ \\
\hline & PARP & Iniparib + irinotecan & None & $\begin{array}{l}\text { NCT01173497 } \\
\text { Phase II }\end{array}$ \\
\hline & Radiation & $\mathrm{PCl}$ & Observation & $\begin{array}{l}\text { NCT02448576 } \\
\text { Phase III }\end{array}$ \\
\hline $\begin{array}{l}\text { Hormone receptor- } \\
\text { positive }\end{array}$ & CDK4/6 & Abemaciclib & None & $\begin{array}{l}\text { NCT02308020 } \\
\text { Phase II }\end{array}$ \\
\hline
\end{tabular}

$C D K$ cyclin-dependent kinase, $H E R 2$ human epidermal growth factor receptor 2, $m T O R$ mammalian target of rapamycin, $P A R P$ poly ADP ribose polymerase, $P C I$ prophylactic cranial irradiation, $P I 3 K$ phosphatidylinositol 3-kinase, SRS stereotactic radiosurgery, VEGF vascular endothelial growth factor, WBRT whole-brain radiation therapy

\section{Authors' contributions}

JPL designed the manuscript, did the literature search and prepared the manuscript. BAL revised the manuscript. Both authors wrote the manuscript. Both authors read and approved the final manuscript.

\section{Author details}

${ }^{1}$ University of lowa Holden Comprehensive Cancer Center, University of lowa Hospitals and Clinics, C32 GH, 200 Hawkins Drive, lowa City, IA 52242, USA.

${ }^{2}$ Grupo Oncológico Cooperativo del Sur (GOCS), Rivadavia 360, 8300 Neuquén, Argentina.

\section{Acknowledgements}

We want to thank the University of lowa Libraries for the support for this publication.

\section{Competing interests}

The authors declare that they have no competing interests.

Received: 16 September 2015 Accepted: 9 November 2015

Published online: 24 November 2015

\section{References}

1. Lin NU, Bellon JR, Winer EP. CNS metastases in breast cancer. J Clin Oncol Off J Am Soc Clin Oncol. 2004;22(17):3608-17. doi:10.1200/JCO.2004.01.175.

2. Arslan C, Dizdar O, Altundag K. Systemic treatment in breastcancer patients with brain metastasis. Expert Opin Pharmacother. 2010;11(7):1089-100. doi:10.1517/14656561003702412.

3. Weil RJ, Palmieri DC, Bronder JL, Stark AM, Steeg PS. Breast cancer metastasis to the central nervous system. Am J Pathol. 2005;167(4):913-20. doi:10.1016/S0002-9440(10)61180-7.

4. Nguyen DX, Bos PD, Massague J. Metastasis: from dissemination to organspecific colonization. Nat Rev Cancer. 2009;9(4):274-84. doi:10.1038/ $\operatorname{nrc} 2622$.
5. Leone JP, Lee AV, Brufsky AM. Prognostic factors and survival of patients with brain metastasis from breast cancer who underwent craniotomy. Cancer Med. 2015:4(7):989-94. doi:10.1002/cam4.439.

6. Gabos Z, Sinha R, Hanson J, Chauhan N, Hugh J, Mackey JR, et al. Prognostic significance of human epidermal growth factor receptor positivity for the development of brain metastasis after newly diagnosed breast cancer. J Clin Oncol Off J Am Soc Clin Oncol. 2006;24(36):5658-63. doi:10.1200/JCO.2006.07.0250.

7. Tham YL, Sexton K, Kramer R, Hilsenbeck S, Elledge R. Primary breast cancer phenotypes associated with propensity for central nervous system metastases. Cancer. 2006;107(4):696-704. doi:10.1002/cncr.22041.

8. Pestalozzi BC, Zahrieh D, Price KN, Holmberg SB, Lindtner J, Collins J, et al. Identifying breast cancer patients at risk for central nervous system (CNS) metastases in trials of the International Breast Cancer Study Group (IBCSG). Ann Oncol Off J Eur Soc Med Oncol/ESMO. 2006;17(6):935-44. doi:10.1093/annonc/mdl064.

9. Nam BH, Kim SY, Han HS, Kwon Y, Lee KS, Kim TH, et al. Breast cancer subtypes and survival in patients with brain metastases. Breast Cancer Res BCR. 2008;10(1):R20. doi:10.1186/bcr1870.

10. Aversa C, Rossi V, Geuna E, Martinello R, Milani A, Redana S, et al. Metastatic breast cancer subtypes and central nervous system metastases. Breast. 2014;23(5):623-8. doi:10.1016/j.breast.2014.06.009.

11. Sperduto PW, Kased N, Roberge D, Chao ST, Shanley R, Luo X, et al. The effect of tumor subtype on the time from primary diagnosis to development of brain metastases and survival in patients with breast cancer. J Neuro-Oncol. 2013;112(3):467-72. doi:10.1007/ s11060-013-1083-9.

12. Lee SS, Ahn JH, Kim MK, Sym SJ, Gong G, Ahn SD, et al. Brain metastases in breast cancer: prognostic factors and management. Breast Cancer Res Treat. 2008;111(3):523-30. doi:10.1007/s10549-007-9806-2.

13. Ogawa K, Yoshii Y, Nishimaki T, Tamaki N, Miyaguni T, Tsuchida Y, et al. Treatment and prognosis of brain metastases from breast cancer. J Neuro-Oncol. 2008;86(2):231-8. doi:10.1007/s11060-007-9469-1.

14. Sperduto PW, Kased N, Roberge D, Xu Z, Shanley R, Luo X, et al. Effect of tumor subtype on survival and the graded prognostic assessment for 
patients with breast cancer and brain metastases. Int J Radiat Oncol Biol Phys. 2012;82(5):2111-7. doi:10.1016/j.jirobp.2011.02.027.

15. Klos KJ, O'Neill BP. Brain metastases. Neurol. 2004;10(1):31-46. doi:10.1097/01.nrl.0000106922.83090.71.

16. Dawood S, Broglio K, Esteva FJ, Ibrahim NK, Kau SW, Islam R, et al. Defining prognosis for women with breast cancer and CNS metastases by HER2 status. Ann Oncol Off J Eur Soc Med Oncol/ESMO. 2008;19(7):1242-8. doi:10.1093/annonc/mdn036.

17. Lin NU, Claus E, Sohl J, Razzak AR, Arnaout A, Winer EP. Sites of distant recurrence and clinical outcomes in patients with metastatic triple-negative breast cancer: high incidence of central nervous system metastases. Cancer. 2008;113(10):2638-45. doi:10.1002/cncr.23930.

18. Gil-Gil MJ, Martinez-Garcia M, Sierra A, Conesa G, Del Barco S, GonzalezJimenez $S$, et al. Breast cancer brain metastases: a review of the literature and a current multidisciplinary management guideline. Clin Transl Onco Off Publ Fed Span Oncol Soc Natl Cancer Inst Mexico. 2014;16(5):436-46. doi:10.1007/s12094-013-1110-5.

19. Niwinska A, Pogoda K, Murawska M, Niwinski P. Factors influencing survival in patients with breast cancer and single or solitary brain metastasis. Eur J Surg Oncol J Eur Soc Surg Oncol Br Assoc Surg Oncol. 2011;37(7):635-42. doi:10.1016/j.ejso.2011.05.002.

20. Niwinska A, Murawska M, Pogoda K. Breast cancer brain metastases: differences in survival depending on biological subtype, RPA RTOG prognostic class and systemic treatment after whole-brain radiotherapy (WBRT). Ann Oncol Off J Eur Soc Med Oncol/ESMO. 2010;21(5):942-8. doi:10.1093/annonc/mdp407.

21. Niikura N, Hayashi N, Masuda N, Takashima S, Nakamura R, Watanabe K, et al. Treatment outcomes and prognostic factors for patients with brain metastases from breast cancer of each subtype: a multicenter retrospective analysis. Breast Cancer Res Treat. 2014;147(1):103-12. doi:10.1007/ s10549-014-3090-8.

22. Anders CK, Deal AM, Miller CR, Khorram C, Meng H, Burrows E, et al. The prognostic contribution of clinical breast cancer subtype, age, and race among patients with breast cancer brain metastases. Cancer. 2011;117(8):1602-11. doi:10.1002/cncr.25746.

23. Melisko ME, Moore DH, Sneed PK, De Franco J, Rugo HS. Brain metastases in breast cancer: clinical and pathologic characteristics associated with improvements in survival. J Neuro-oncol. 2008;88(3):359-65. doi:10.1007/ s11060-008-9578-5.

24. Lentzsch S, Reichardt P, Weber F, Budach V, Dorken B. Brain metastases in breast cancer: prognostic factors and management. Eur J Cancer. 1999;35(4):580-5.

25. Hung MH, Liu CY, Shiau CY, Hsu CY, Tsai YF, Wang YL, et al. Effect of age and biological subtype on the risk and timing of brain metastasis in breast cancer patients. PloS One. 2014;9(2):e89389. doi:10.1371/journal. pone.0089389.

26. Nieder C, Marienhagen K, Astner ST, Molls M. Prognostic scores in brain metastases from breast cancer. BMC Cancer. 2009;9:105 doi:10.1186/1471-2407-9-105.

27. Sperduto PW, Berkey B, Gaspar LE, Mehta M, Curran W. A new prognostic index and comparison to three other indices for patients with brain metastases: an analysis of 1,960 patients in the RTOG database. Int J Radiat Oncol Biol Phys. 2008;70(2):510-4. doi:10.1016/j.jirobp.2007.06.074.

28. Sperduto CM, Watanabe Y, Mullan J, Hood T, Dyste G, Watts C, et al. A validation study of a new prognostic index for patients with brain metastases: the Graded Prognostic Assessment. J Neurosurg. 2008;109(Suppl):879. doi:10.3171/JNS/2008/109/12/S14

29. Subbiah IM, Lei X, Weinberg JS, Sulman EP, Chavez-MacGregor M, Tripathy $D$, et al. Validation and development of a modified breast graded prognostic assessment as a tool for survival in patients with breast cancer and brain metastases. J Clin Oncol Off J Am Soc Clin Oncol. 2015;33(20):223945. doi:10.1200/JCO.2014.58.8517.

30. Patchell RA, Tibbs PA, Walsh JW, Dempsey RJ, Maruyama Y, Kryscio RJ, et al. A randomized trial of surgery in the treatment of single metastases to the brain. N Engl J Med. 1990;322(8):494-500. doi:10.1056/ NEJM199002223220802.

31. Vecht CJ, Haaxma-Reiche H, Noordijk EM, Padberg GW, Voormolen JH, Hoekstra FH, et al. Treatment of single brain metastasis: radiotherapy alone or combined with neurosurgery? Ann Neurol. 1993;33(6):583-90. doi:10.1002/ana.410330605
32. Mintz AH, Kestle J, Rathbone MP, Gaspar L, Hugenholtz H, Fisher B, et al. A randomized trial to assess the efficacy of surgery in addition to radiotherapy in patients with a single cerebral metastasis. Cancer 1996;78(7):1470-6.

33. Sause WT, Crowley JJ, Morantz R, Rotman M, Mowry PA, Bouzaglou A, et al. Solitary brain metastasis: results of an RTOG/SWOG protocol evaluation surgery +RT versus RT alone. Am J Clin Oncol. 1990;13(5):427-32.

34. Ampil FL, Nanda A, Willis BK, Nandy I, Meehan R. Metastatic disease in the cerebellum. The LSU experience in 1981-1993. Am J Clin Oncol. 1996;19(5):509-11.

35. Rades D, Kieckebusch S, Haatanen T, Lohynska R, Dunst J, Schild SE. Surgical resection followed by whole brain radiotherapy versus whole brain radiotherapy alone for single brain metastasis. Int J Radiat Oncol Biol Phys. 2008;70(5):1319-24. doi:10.1016/j.jirobp.2007.08.009.

36. Kondziolka D, Patel A, Lunsford LD, Kassam A, Flickinger JC. Stereotactic radiosurgery plus whole brain radiotherapy versus radiotherapy alone for patients with multiple brain metastases. Int J Radiat Oncol Biol Phys. 1999:45(2):427-34.

37. Sneed PK, Suh JH, Goetsch SJ, Sanghavi SN, Chappell R, Buatti JM, et al. A multi-institutional review of radiosurgery alone vs. radiosurgery with whole brain radiotherapy as the initial management of brain metastases. Int J Radiat Oncol Biol Phys. 2002;53(3):519-26.

38. Linskey ME, Andrews DW, Asher AL, Burri SH, Kondziolka D, Robinson $\mathrm{PD}$, et al. The role of stereotactic radiosurgery in the management of patients with newly diagnosed brain metastases: a systematic review and evidence-based clinical practice guideline. J Neuro-oncol. 2010;96(1):4568. doi:10.1007/s11060-009-0073-4.

39. Andrews DW, Scott CB, Sperduto PW, Flanders AE, Gaspar LE, Schell MC, et al. Whole brain radiation therapy with or without stereotactic radiosurgery boost for patients with one to three brain metastases: phase III results of the RTOG 9508 randomised trial. Lancet. 2004;363(9422):166572. doi:10.1016/S0140-6736(04)16250-8.

40. Roberge D, Petrecca K, El Refae M, Souhami L. Whole-brain radiotherapy and tumor bed radiosurgery following resection of solitary brain metastases. J Neuro-oncol. 2009;95(1):95-9. doi:10.1007/s11060-009-9899-z.

41. Aoyama H, Shirato H, Tago M, Nakagawa K, Toyoda T, Hatano K, et al. Stereotactic radiosurgery plus whole-brain radiation therapy vs stereotactic radiosurgery alone for treatment of brain metastases: a randomized controlled trial. Jama. 2006;295(21):2483-91. doi:10.1001/jama.295.21.2483.

42. Chang EL, Wefel JS, Hess KR, Allen PK, Lang FF, Kornguth DG, et al. Neurocognition in patients with brain metastases treated with radiosurgery or radiosurgery plus whole-brain irradiation: a randomised controlled trial. Lancet Oncol. 2009;10(11):1037-44. doi:10.1016/S1470-2045(09)70263-3.

43. Tsao M, Xu W, Sahgal A. A meta-analysis evaluating stereotactic radiosurgery, whole-brain radiotherapy, or both for patients presenting with a limited number of brain metastases. Cancer. 2012;118(9):2486-93. doi:10.1002/cncr.26515.

44. Yamamoto M, Serizawa T, Shuto T, Akabane A, Higuchi Y, Kawagishi J, et al. Stereotactic radiosurgery for patients with multiple brain metastases (JLGK0901): a multi-institutional prospective observational study. Lancet Oncol. 2014;15(4):387-95. doi:10.1016/S1470-2045(14)70061-0.

45. Chang WS, Kim HY, Chang JW, Park YG, Chang JH. Analysis of radiosurgical results in patients with brain metastases according to the number of brain lesions: is stereotactic radiosurgery effective for multiple brain metastases? J Neurosurg. 2010;113(Suppl):73-8.

46. Yamamoto M, Kawabe T, Sato Y, Higuchi Y, Nariai T, Barfod BE, et al. A casematched study of stereotactic radiosurgery for patients with multiple brain metastases: comparing treatment results for $1-4 \mathrm{vs} \geq 5$ tumors: clinical article. J Neurosurg. 2013;118(6):1258-68. doi:10.3171/2013.3.JNS121900.

47. Ojerholm E, Lee JY, Kolker J, Lustig R, Dorsey JF, Alonso-Basanta M. Gamma Knife radiosurgery to four or more brain metastases in patients without prior intracranial radiation or surgery. Cancer Med. 2014;3(3):56571. doi:10.1002/cam4.206.

48. Kaal EC, Niel CG, Vecht CJ. Therapeutic management of brain metastasis. Lancet Neurol. 2005;4(5):289-98. doi:10.1016/S1474-4422(05)70072-7.

49. Patchell RA, Tibbs PA, Regine WF, Dempsey RJ, Mohiuddin M, Kryscio RJ, et al. Postoperative radiotherapy in the treatment of single metastases to the brain: a randomized trial. Jama. 1998;280(17):1485-9.

50. Kocher M, Soffietti R, Abacioglu U, Villa S, Fauchon F, Baumert BG, et al. Adjuvant whole-brain radiotherapy versus observation after radiosurgery 
or surgical resection of one to three cerebral metastases: results of the EORTC 22952-26001 study. J Clin Oncol Off J Am Soc Clin Oncol. 2011;29(2):134-41. doi:10.1200/JCO.2010.30.1655.

51. Soffietti R, Kocher M, Abacioglu UM, Villa S, Fauchon F, Baumert BG, et al. A European Organisation for research and treatment of cancer phase III trial of adjuvant whole-brain radiotherapy versus observation in patients with one to three brain metastases from solid tumors after surgical resection or radiosurgery: quality-of-life results. J Clin Oncol Off J Am Soc Clin Oncol. 2013;31(1):65-72. doi:10.1200/JCO.2011.41.0639.

52. Li J, Bentzen SM, Renschler M, Mehta MP. Regression after whole-brain radiation therapy for brain metastases correlates with survival and improved neurocognitive function. J Clin Oncol Off J Am Soc Clin Oncol. 2007;25(10):1260-6. doi:10.1200/JCO.2006.09.2536.

53. Aoyama H, Tago M, Kato N, Toyoda T, Kenjyo M, Hirota S, et al. Neurocognitive function of patients with brain metastasis who received either whole brain radiotherapy plus stereotactic radiosurgery or radiosurgery alone. Int J Radiat Oncol Biol Phys. 2007;68(5):1388-95. doi:10.1016/j. ijrobp.2007.03.048.

54. Brown PD, Asher AL, Ballman KV, Farace E, Cerhan JH, Anderson SK, et al. NCCTG N0574 (Alliance): a phase III randomized trial of whole brain radiation therapy (WBRT) in addition to radiosurgery (SRS) in patients with 1-3 brain metastases. J Clin Oncol Off J Am Soc Clin Oncol. 2015;33(suppl; abstr LBA4).

55. Kaplan MA, Isikdogan A, Koca D, Kucukoner M, Gumusay O, Yildiz R, et al. Biological subtypes and survival outcomes in breast cancer patients with brain metastases (study of the Anatolian Society of Medical Oncology). Oncology. 2012;83(3):141-50. doi:10.1159/000338782.

56. Colomer R, Cosos D, Del Campo JM, Boada M, Rubio D, Salvador L. Brain metastases from breast cancer may respond to endocrine therapy. Breast Cancer Res Treat. 1988;12(1):83-6.

57. Pors H, von Eyben FE, Sorensen OS, Larsen M. Longterm remission of multiple brain metastases with tamoxifen. J Neuro-oncol. 1991;10(2):173-7.

58. Stewart DJ, Dahrouge S. Response of brain metastases from breast cancer to megestrol acetate: a case report. J Neuro-oncol. 1995;24(3):299-301.

59. Madhup R, Kirti S, Bhatt ML, Srivastava PK, Srivastava M, Kumar S. Letrozole for brain and scalp metastases from breast cancer-a case report. Breast. 2006;15(3):440-2. doi:10.1016/j.breast.2005.07.006.

60. Goyal S, Puri T, Julka PK, Rath GK. Excellent response to letrozole in brain metastases from breast cancer. Acta Neurochir. 2008;150(6):613-4 (discussion 4-5). doi:10.1007/s00701-008-1576-z.

61. Ito K, Ito T, Okada T, Watanabe T, Gomi K, Kanai T, et al. A case of brain metastases from breast cancer that responded to anastrozole monotherapy. Breast J. 2009;15(4):435-7. doi:10.1111/j.1524-4741.2009.00756.x.

62. Lien EA, Wester K, Lonning PE, Solheim E, Ueland PM. Distribution of tamoxifen and metabolites into brain tissue and brain metastases in breast cancer patients. Br J Cancer. 1991;63(4):641-5.

63. Swain SM, Baselga J, Kim SB, Ro J, Semiglazov V, Campone M, et al. Pertuzumab, trastuzumab, and docetaxel in HER2-positive metastatic breast cancer. N Engl J Med. 2015;372(8):724-34. doi:10.1056/NEJMoa1413513.

64. Pestalozzi BC, Brignoli S. Trastuzumab in CSF. J Clin Oncol Off J Am Soc Clin Oncol. 2000;18(11):2349-51.

65. Stemmler HJ, Heinemann V. Central nervous system metastases in HER2-overexpressing metastatic breast cancer: a treatment challenge. Oncol. 2008;13(7):739-50. doi:10.1634/theoncologist.2008-0052.

66. Dijkers EC, Oude Munnink TH, Kosterink JG, Brouwers AH, Jager PL, de Jong JR, et al. Biodistribution of 89Zr-trastuzumab and PET imaging of HER2-positive lesions in patients with metastatic breast cancer. Clin Pharmacol Ther. 2010;87(5):586-92. doi:10.1038/clpt.2010.12.

67. Tamura K, Kurihara H, Yonemori K, Tsuda H, Suzuki J, Kono Y, et al. 64Cu-DOTA-trastuzumab PET imaging in patients with HER2-positive breast cancer. J Nucl Med Off Publ Soc Nucl Med. 2013;54(11):1869-75. doi:10.2967/jnumed.112.118612.

68. Bartsch R, Rottenfusser A, Wenzel C, Dieckmann K, Pluschnig U, Altorjai G, et al. Trastuzumab prolongs overall survival in patients with brain metastases from Her2 positive breast cancer. J Neuro-oncol. 2007;85(3):311-7. doi:10.1007/s11060-007-9420-5.

69. Brufsky AM, Mayer M, Rugo HS, Kaufman PA, Tan-Chiu E, Tripathy D, et al. Central nervous system metastases in patients with HER2-positive metastatic breast cancer: incidence, treatment, and survival in patients from registHER. Clin Cancer Res Off J Am Assoc Cancer Res. 2011;17(14):483443. doi:10.1158/1078-0432.CCR-10-2962.
70. Yap YS, Cornelio GH, Devi BC, Khorprasert C, Kim SB, Kim TY, et al. Brain metastases in Asian HER2-positive breast cancer patients: anti-HER2 treatments and their impact on survival. Br J Cancer. 2012;107(7):1075-82. doi:10.1038/bjc.2012.346.

71. Park YH, Park MJ, Ji SH, Yi SY, Lim DH, Nam DH, et al. Trastuzumab treatment improves brain metastasis outcomes through control and durable prolongation of systemic extracranial disease in HER2-overexpressing breast cancer patients. Br J Cancer. 2009;100(6):894-900. doi:10.1038/ sj.bjc.6604941.

72. Lin NU, Carey LA, Liu MC, Younger J, Come SE, Ewend M, et al. Phase II trial of lapatinib for brain metastases in patients with human epidermal growth factor receptor 2-positive breast cancer. J Clin Oncol Off J Am Soc Clin Oncol. 2008;26(12):1993-9. doi:10.1200/JCO.2007.12.3588.

73. Lin NU, Dieras V, Paul D, Lossignol D, Christodoulou C, Stemmler HJ, et al. Multicenter phase II study of lapatinib in patients with brain metastases from HER2-positive breast cancer. Clin Cancer Res Off J Am Assoc Cancer Res. 2009;15(4):1452-9. doi:10.1158/1078-0432.CCR-08-1080.

74. Sutherland S, Ashley S, Miles D, Chan S, Wardley A, Davidson N, et al. Treatment of HER2-positive metastatic breast cancer with lapatinib and capecitabine in the lapatinib expanded access programme, including efficacy in brain metastases-the UK experience. Br J Cancer. 2010;102(6):995-1002. doi:10.1038/sj.bjc.6605586.

75. Metro G, Foglietta J, Russillo M, Stocchi L, Vidiri A, Giannarelli D, et al. Clinical outcome of patients with brain metastases from HER2-positive breast cancer treated with lapatinib and capecitabine. Ann Oncol Off J Eur Soc Med Oncol/ESMO. 2011;22(3):625-30. doi:10.1093/annonc/mdq434.

76. Iwata H, Narabayashi M, Ito Y, Saji S, Fujiwara Y, Usami S, et al. A phase II study of lapatinib for brain metastases in patients with HER2-overexpressing breast cancer following trastuzumab based systemic therapy and cranial radiotherapy: subset analysis of Japanese patients. Int J Clin Oncol. 2013;18(4):621-8. doi:10.1007/s10147-012-0444-2.

77. Ro J, Park S, Kim S, Kim TY, Im YH, Rha SY, et al. Clinical outcomes of HER2positive metastatic breast cancer patients with brain metastasis treated with lapatinib and capecitabine: an open-label expanded access study in Korea. BMC Cancer. 2012;12:322. doi:10.1186/1471-2407-12-322.

78. Bachelot T, Romieu G, Campone M, Dieras V, Cropet C, Dalenc F, et al. Lapatinib plus capecitabine in patients with previously untreated brain metastases from HER2-positive metastatic breast cancer (LANDSCAPE): a single-group phase 2 study. Lancet Oncol. 2013;14(1):64-71. doi:10.1016/ S1470-2045(12)70432-1.

79. Cameron D, Casey M, Press M, Lindquist D, Pienkowski T, Romieu CG, et al. A phase III randomized comparison of lapatinib plus capecitabine versus capecitabine alone in women with advanced breast cancer that has progressed on trastuzumab: updated efficacy and biomarker analyses. Breast Cancer Res Treat. 2008;112(3):533-43. doi:10.1007/s10549-007-9885-0.

80. Pivot X, Manikhas A, Zurawski B, Chmielowska E, Karaszewska B, Allerton R, et al. CEREBEL (EGF111438): a phase III, randomized, open-label study of lapatinib plus capecitabine versus trastuzumab plus capecitabine in patients with human epidermal growth factor receptor 2-positive metastatic breast cancer. J Clin Oncol Off J Am Soc Clin Oncol. 2015;33(14):1564-73. doi:10.1200/JCO.2014.57.1794.

81. Verma S, Miles D, Gianni L, Krop IE, Welslau M, Baselga J, et al. Trastuzumab emtansine for HER2-positive advanced breast cancer. N Engl J Med. 2012;367(19):1783-91. doi:10.1056/NEJMoa1209124.

82. Krop IE, Lin NU, Blackwell K, Guardino E, Huober J, Lu M, et al. Trastuzumab emtansine (T-DM1) versus lapatinib plus capecitabine in patients with HER2-positive metastatic breast cancer and central nervous system metastases: a retrospective, exploratory analysis in EMILIA. Ann Oncol Off J Eur Soc Med Oncol/ESMO. 2015;26(1):113-9. doi:10.1093/annonc/mdu486.

83. Swain SM, Baselga J, Miles D, Im YH, Quah C, Lee LF, et al. Incidence of central nervous system metastases in patients with HER2-positive metastatic breast cancer treated with pertuzumab, trastuzumab, and docetaxel: results from the randomized phase III study CLEOPATRA. Ann Oncol Off J Eur Soc Med Oncol/ESMO. 2014;25(6):1116-21. doi:10.1093/ annonc/mdu133.

84. Ramakrishna N, Temin S, Chandarlapaty S, Crews JR, Davidson NE, Esteva FJ, et al. Recommendations on disease management for patients with advanced human epidermal growth factor receptor 2-positive breast cancer and brain metastases: american Society of Clinical Oncology clinical practice guideline. J Clin Oncol Off J Am Soc Clin Oncol. 2014;32(19):2100-8. doi:10.1200/JCO.2013.54.0955. 
85. Giordano SH, Temin S, Kirshner JJ, Chandarlapaty S, Crews JR, Davidson $\mathrm{NE}$, et al. Systemic therapy for patients with advanced human epiderma growth factor receptor 2-positive breast cancer: American Society of Clinical Oncology clinical practice guideline. J Clin Oncol Off J Am Soc Clin Oncol. 2014;32(19):2078-99. doi:10.1200/JCO.2013.54.0948.

86. Rosner D, Nemoto T, Lane WW. Chemotherapy induces regression of brain metastases in breast carcinoma. Cancer. 1986;58(4):832-9.

87. Boogerd W, Dalesio O, Bais EM, van der Sande JJ. Response of brain metastases from breast cancer to systemic chemotherapy. Cancer. 1992;69(4):972-80.

88. Franciosi V, Cocconi G, Michiara M, Di Costanzo F, Fosser V, Tonato M, et al. Front-line chemotherapy with cisplatin and etoposide for patients with brain metastases from breast carcinoma, nonsmall cell lung carcinoma, or malignant melanoma: a prospective study. Cancer. 1999;85(7):1599-605.

89. Lorusso V, Galetta D, Giotta F, Rinaldi A, Romito S, Brunetti C, et al. Topotecan in the treatment of brain metastases. A phase II study of GOIM (Gruppo Oncologico dell'Italia Meridionale). Anticancer Res. 2006;26(3B):2259-63.

90. Trudeau ME, Crump M, Charpentier D, Yelle L, Bordeleau L, Matthews $\mathrm{S}$, et al. Temozolomide in metastatic breast cancer (MBC): a phase II trial of the National Cancer Institute of Canada-Clinical Trials Group (NCIC-CTG). Ann Oncol Off J Eur Soc Med Oncol/ESMO. 2006;17(6):952-6. doi:10.1093/annonc/mdl056.

91. Christodoulou C, Bafaloukos D, Linardou H, Aravantinos G, Bamias A, Carina M, et al. Temozolomide (TMZ) combined with cisplatin (CDDP) in patients with brain metastases from solid tumors: a Hellenic Cooperative Oncology Group (HeCOG) Phase II study. J Neuro-oncol. 2005;71(1):61-5. doi:10.1007/s11060-004-9176-0.

92. Rivera E, Meyers C, Groves M, Valero V, Francis D, Arun B, et al. Phase I study of capecitabine in combination with temozolomide in the treatment of patients with brain metastases from breast carcinoma. Cancer. 2006;107(6):1348-54. doi:10.1002/cncr.22127.

93. Ekenel M, Hormigo AM, Peak S, Deangelis LM, Abrey LE. Capecitabine therapy of central nervous system metastases from breast cancer. J Neuro-oncol. 2007;85(2):223-7. doi:10.1007/s11060-007-9409-0.

94. Lin NU, Gelman RS, Younger WJ, Sohl J, Freedman RA, Sorensen AG, et al. Phase II trial of carboplatin (C) and bevacizumab (BEV) in patients (pts) with breast cancer brain metastases (BCBM). J Clin Oncol Off J Am Soc Clin Oncol. 2013;31(suppl; abstr 513).

95. Lu YS, Chen WW, Lin CH, Tseng LM, Yeh DC, Wu PF, et al. Bevacizumab, etoposide, and cisplatin (BEEP) in brain metastases of breast cancer progressing from radiotherapy: Results of the first stage of a multicenter phase II study. J Clin Oncol Off J Am Soc Clin Oncol. 2012;30(suppl; abstr 1079).

96. Leone JP, Bhargava R, Theisen BK, Hamilton RL, Lee AV, Brufsky AM. Expression of high affinity folate receptor in breast cancer brain metastasis. Oncotarget. 2015;6(30):30327-33. doi:10.18632/oncotarget.4639.

97. Adamo B, Deal AM, Burrows E, Geradts J, Hamilton E, Blackwell KL, et al. Phosphatidylinositol 3-kinase pathway activation in breast cancer brain metastases. Breast Cancer Res BCR. 2011;13(6):R125. doi:10.1186/bcr3071.

\section{Submit your next manuscript to BioMed Central and take full advantage of:}

- Convenient online submission

- Thorough peer review

- No space constraints or color figure charges

- Immediate publication on acceptance

- Inclusion in PubMed, CAS, Scopus and Google Scholar

- Research which is freely available for redistribution

Submit your manuscript at

www.biomedcentral.com/submit

C BioMed Central 